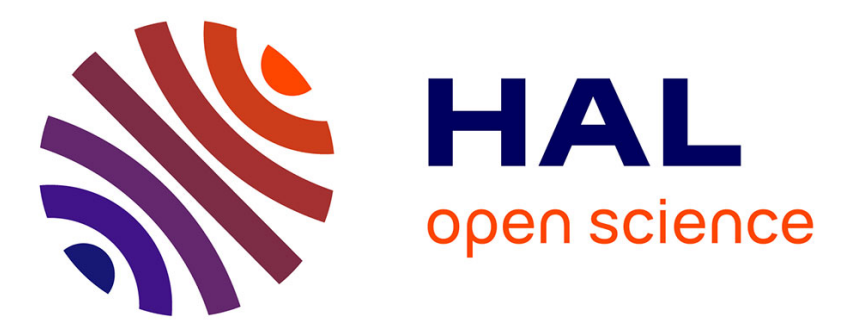

\title{
A versatile approach, considering tool wear, to simulate undercut error when turning thin-walled workpieces
}

Bastien Toubhans, Philippe Lorong, Fabien Viprey, Guillaume Fromentin, Habib Karaouni

\section{- To cite this version:}

Bastien Toubhans, Philippe Lorong, Fabien Viprey, Guillaume Fromentin, Habib Karaouni. A versatile approach, considering tool wear, to simulate undercut error when turning thin-walled workpieces. International Journal of Advanced Manufacturing Technology, 2021, 115, pp.1919-1929. 10.1007/s00170-021-07243-8 . hal-03324945

\section{HAL Id: hal-03324945 \\ https://hal.science/hal-03324945}

Submitted on 24 Aug 2021

HAL is a multi-disciplinary open access archive for the deposit and dissemination of scientific research documents, whether they are published or not. The documents may come from teaching and research institutions in France or abroad, or from public or private research centers.
L'archive ouverte pluridisciplinaire $\mathbf{H A L}$, est destinée au dépôt et à la diffusion de documents scientifiques de niveau recherche, publiés ou non, émanant des établissements d'enseignement et de recherche français ou étrangers, des laboratoires publics ou privés. 


\title{
A versatile approach, considering tool wear, to simulate undercut error when turning thin-walled workpieces
}

\author{
Bastien Toubhans $^{1,2}$ (i) $\cdot$ Philippe Lorong $^{3} \cdot$ Fabien Viprey $^{1} \cdot$ Guillaume Fromentin ${ }^{1} \cdot$ Habib Karaouni $^{2}$
}

\begin{abstract}
In-process workpiece elastic deflection is the major source of geometrical error when machining low-stiffness workpieces. It creates an undercut error which needs to be corrected by time-consuming and labour-intensive operations. For this reason, cutting process simulation is growing in interest. To do so, a model representing the workpiece flexibility is coupled with a model to predict the applied cutting forces. For a given tool-material set, these cutting forces depend on the cut section, which therefore depends on current deflection of the part during machining, but also on the level of tool wear. This research work focuses on developing a general coupling approach to tackle this challenge. The case study is the finish turning on thin Inconel 718 discs. The cutting forces are predicted by a mechanistic model taking tool wear into account. The wear effect is expressed using the cumulative removed volume. The workpiece stiffness is determined with a reduced model using a modal basis. When dealing with large workpieces, it results in a remarkable computing time reduction during the time domain simulation. Cutting tests with varying engagements are simulated in a dexel-based versatile framework and undercut errors are compared to experimental observations.
\end{abstract}

Keywords Machining simulation $\cdot$ Cutting force model $\cdot$ Tool wear $\cdot$ Elastic deflection $\cdot$ Turning

\section{Introduction}

Elastic workpiece deflection related to cutting forces is one of the major responsible for dimensional errors when machining

Bastien Toubhans

bastien.toubhans@ensam.eu; bastien.toubhans@free.fr

Philippe Lorong

Philippe.lorong@ensam.eu

Fabien Viprey

Fabien.viprey@ensam.eu

Guillaume Fromentin

Guillaume.fromentin@ensam.eu

Habib Karaouni

Habib.karaouni@safrangroup.com

1 Arts et Metiers Institute of Technology, LABOMAP, UBFC, HESAM Université, 1 rue porte de Paris, F-71250 Cluny, France

2 Safran S.A., Research \& Technology Center, F-78772 Magny-les-Hameaux, France

3 Laboratoire PIMM, Arts et Metiers Institute of Technology, CNRS, Cnam, HESAM Universite, 151 boulevard de l'Hopital, 75013 Paris, France thin workpieces. As the part is pushed away from the tool during the cutting process, an undercut error appears. Some aerospace parts such as turbine discs are large and contain low-stiffness portions which need to be machined to tight tolerances. The process simulation on such workpieces is complex, and there is a need for the development of comprehensive, cost-effective approaches to deal with this issue. Other phenomena may induce part distortion during machining and thus dimensional errors on the finished part: clamping, inertial effects or vibrations, initial residual stresses rebalancing following matter removal and machining-induced residual stresses. In many cases, these latter phenomena have a negligible effect on cutting forces. This research work focuses on undercut modelling related to static workpiece deflection under cutting forces.

Three major issues are identified: the varying workpiece stiffness along the tool path due to its intrinsic geometry; the varying stiffness due to material removal and the cutting force evolution due to tool wear. The varying stiffness due to material removal is not handled in this study as its effect is marginal in most finishing operation, where a small quantity of material is removed. The majority of studies dealing with undercut are about the milling of thin workpieces such as large thin-walled structural parts or complex shapes such as turbine 
blades [1]-[5]. Several research works are available to predict and compensate the undercut error. Most of them are offline methodologies and rely on the coupling of a workpiece stiffness model and a cutting force model. An iterative algorithm based on a convergence loop at successive tool positions is often used to either model the workpiece deflection or to generate a compensated tool path prior to machining [1, 3, 6-8].

Concerning the first issue, varying workpiece stiffness along the tool path, numerous researchers use finite element methods (FEM) to simulate workpiece displacement under cutting forces $[1,2,9]$. For simpler workpieces, the use of analytical models may be appropriate. A turbine blade is described using the plate theory in [3]. FEM and beam models are tested to describe the dynamic response of an end mill in [8]. The beam theory appears to be a suitable compromise for accuracy and computing time in this case. However, these approaches are either too specific to one application or timeconsuming when working with large FE models. In order to model the dynamic response of a machining system, it is possible to reduce the complexity of the model using a RayleighRitz approach [10]. It consists in describing the dynamic response of a system using only the first vibration modes.

The second problematic (i.e. the evolution of cutting forces with tool life) is critical when working with difficult to cut material such as Inconel 718. In most studies, only the passive cutting force, the cutting force component normal to the machined surface, is considered. This simplifying assumption is consolidated because the workpiece stiffness in the direction normal to its surface is generally far inferior to the one in the tangent direction. Moreover, workpiece displacement in the machined surface plane does not modify the uncut chip section contrary to deflection in the normal direction. Then, the problem can be correctly described by the cutting force component and the workpiece stiffness in the normal direction only. Cutting force models are readily available; many of them are derived from Armarego's early work on mechanistic approaches describing cutting parameter and tool geometry. A linear formulation is used in $[1,8]$ to express the normal cutting force using the uncut chip section. A mechanistic model using a linear function of the uncut chip thickness is used in [3]. However, none of the studies deals with undercut prediction by including tool wear effect in modelling. In the case of Inconel 718, tool wear has however a significant impact on cutting forces [11], especially the passive cutting force which can be multiplied by up to 4 during a normal tool life [12]. The role of vibrations on the cutting process and its impact on tool wear has been tackled in [13]. Although vibrations are common when machining flexible workpieces, as evidenced in [14], this study focuses on in-process static workpiece deflection in initial study. This hypothesis is valid here because, for the examples discussed, the measurements carried out showed a low contribution of vibrations to the deflection of the parts being machined.
Regarding correction of undercut, two different approaches are present in the literature: the compensation of workpiece deflection and the control of deflection. On the one hand, the compensation strategies largely rely on modifications of the tool trajectory. In [2], the authors insist on the fact that during a multilayer removal process, the undercut at the previous pass has an effect on the current pass. By introducing the error made at the previous pass in the iterative process, the undercut is reduced and more uniform. On the other hand, the control strategy aims at accurately predicting the deflection to control the error and reduce it. These methods largely rely on the modifications of cutting parameters. For example, [3] propose a variable depth of cut approach to optimise a material removal sequence and not exceed a deflection threshold. Another strategy is used in [1] to homogenise the workpiece deflection by modulating the feed rate. The feed rate and end mill tilt angle are modified in [4] to minimise deflection and vibrations. These offline strategies are elaborated prior to machining.

This research work focuses on the modelling of static inprocess elastic workpiece deflection induced by cutting forces for an operation during which cutting forces significantly increase with tool wear. The main goal is to propose a comprehensive approach to model undercut error occurring when machining low stiffness workpieces. The case study, presented in Section 2, is the finish turning of thin Inconel 718 discs. First, a cutting force model considering tool wear is developed in Section 3. The tool wear effect is expressed in terms of accumulation of local removed material volume. This makes it possible to take into account a variation in the tool/matter engagement without having to modify the cutting law. Then, a method based on the use of a reduced modal basis is proposed to model the variable stiffness along the tool path in Section 4. The solutions are then implemented in a general dexel-based framework, and the case study is simulated in Section 5. The simulated undercut is compared to experimental observations.

\section{Case study}

Face-turning operations are performed on 3-mm-thick Inconel 718 discs. The disc is clamped on a shaft and free to deform from the radial positions 20 to $68.5 \mathrm{~mm}$ (Fig. 1). Cutting forces are continually measured in the machine coordinate system during the pass using a piezoelectric dynamometer and a charge amplifier (ref: Kistler 9121 and 5019). The resulting disc geometry is scanned using two laser sensors after machining (Micro-Epsilon, ref: optoNCDT 1420ILD10). The sensors are placed on either side of the disc. This allows comparing the local disc thickness before and after machining and then to compute the real depth of cut. The average undercut during the first face-turning operation is represented on Fig. 1 for a disc machined with a fresh tool at 


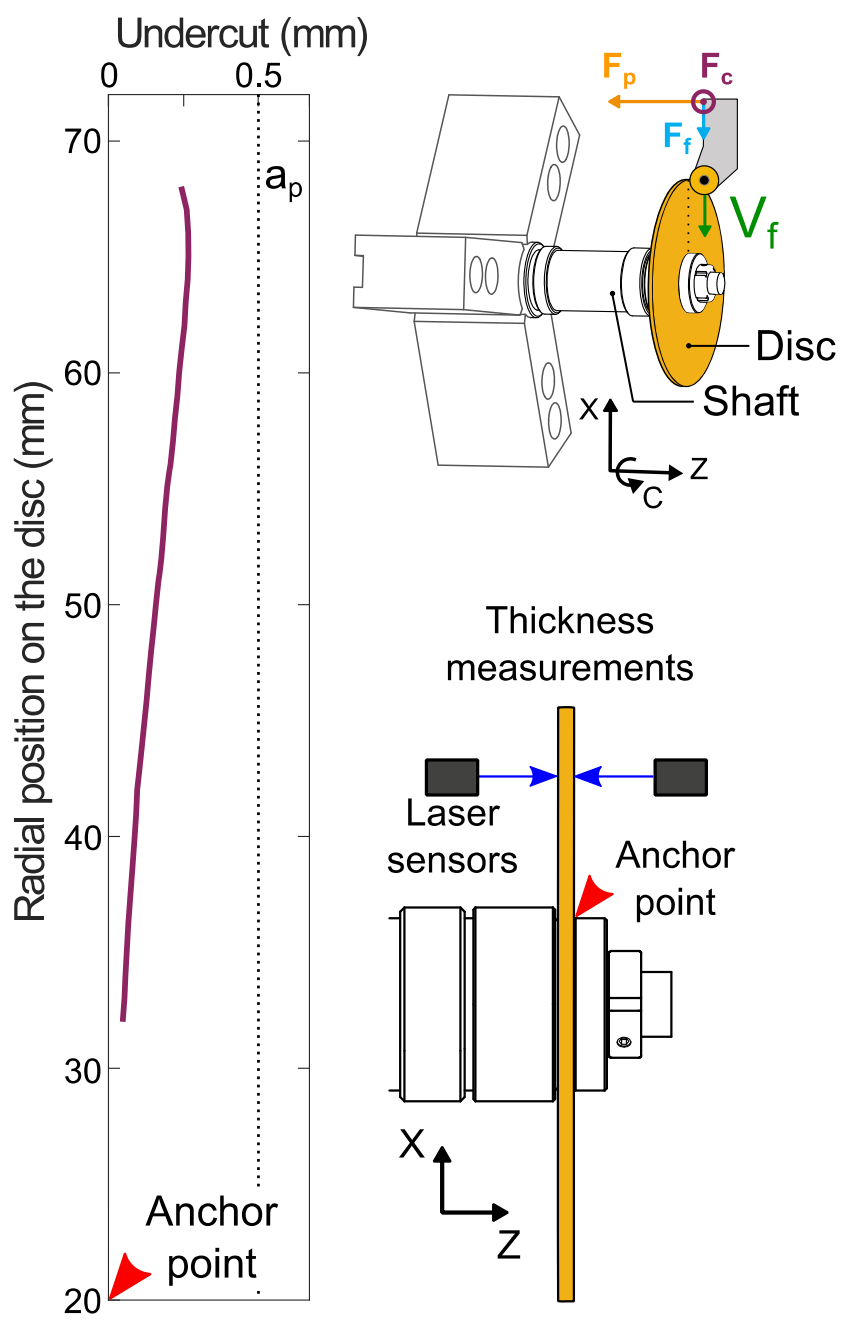

Fig. 1 Average undercut error measured on a disc machined with a fresh tool- $\mathrm{V}_{\mathrm{c}}=52.5 \mathrm{~m} / \mathrm{min}, \mathrm{f}=0.1 \mathrm{~mm} / \mathrm{rev}, \mathrm{a}_{\mathrm{p}}=0.5 \mathrm{~mm}$

$\mathrm{V}_{\mathrm{c}}=52.5 \mathrm{~m} / \mathrm{min}, \mathrm{f}=0.1 \mathrm{~mm} / \mathrm{rev}$ and $\mathrm{a}_{\mathrm{p}}=0.5 \mathrm{~mm}$ under flood cooling lubrication. As can be seen on Fig. 1, the undercut error is not constant. Indeed, the disc stiffness at the tool location is varying along the tool path. The disc is stiffer close to the clamping location.

Additionally, in the case of Inconel 718 and other "hard to cut" materials, cutting forces are highly sensitive to tool wear as highlighted in [12]. The passive cutting force evolution during a similar operation on a rigid workpiece with a constant engagement is shown on Fig. 2. An increasing of the passive cutting force equal to $35 \%$ occurs during the pass.

To sum up, cutting forces evolve during the pass due to varying stiffness causing the tool engagement to vary. Also, tool wear is causing the cutting forces to increase. Thereby, workpiece elastic deflection and cutting forces are coupled. As the workpiece deforms, the cut section is reduced and so are the cutting forces. A stiffness model of the workpiece and a cutting force model considering tool wear must be developed to tackle this issue.

\section{Cutting force model considering tool wear}

In this study, a mechanistic approach is used [12]. Experimental observations of cutting forces during tool life are first presented. Then, a local force model taking tool wear into account is developed.

\subsection{Cutting forces evolution during tool life}

Long face-turning tests are performed on a massive workpiece until the tool is deemed worn, i.e. when the maximal flank wear, VB, reaches $0.3 \mathrm{~mm}$. Flank wear is measured in situ with a digital microscope (ref: Dino-Lite AM7915MZT). Cutting forces are continually measured in the machine coordinate system during the tool life using a piezoelectric dynamometer and a charge amplifier (ref : Kistler 9121 and 5019). Three cutting conditions are tested with a constant cutting speed and depth of cut, respectively, equal to $52.5 \mathrm{~m} / \mathrm{min}$ and $0.5 \mathrm{~mm}$ and different feeds equal to $0.1,0.2$ and 0.35 $\mathrm{mm} / \mathrm{rev}$. As expected, cutting forces increase with tool wear. In the studied case, cutting forces evolution follows the same pattern as the classic tool wear evolution [11] as shown in Fig. 3. Cutting forces rapidly increase during a short running-in period. Then, the increase is almost linear during the controlled wear region. Finally, an inflexion in the cutting forces evolution occurs at the end of the controlled wear region and leads to the end of the tool life. During this last period, cutting forces increase quickly. The passive cutting force growth factors are displayed in Fig. 3 at the end of the controlled wear region and at the end of tool life for different cutting conditions. The passive cutting force $F_{\mathrm{p}}$ may increase by a factor equal to 3.5 during the controlled wear period. In the absence of vibrations, the workpiece elastic deflection is proportional to the passive cutting force. Hence, it is critical to take tool wear into account when modelling cutting forces during the tool life. These tests have been repeated several times and are reproducible during the running in period and the controlled wear region. However, the end of the controlled wear region leading to the end of tool life is unpredictable.

The passive cutting force growth, relative to the initial passive force levels measured with a fresh tool, is plotted against the cumulative removed volume for different cutting tests at different feeds and constant cutting speed and depth of cut in Fig. 4. It appears that the growth slopes are similar for all the tests during the running-in and controlled wear region. Only the end of the controlled wear period differs from one test to another. Consequently, the cumulative removed volume seems to be a suiting indicator to model the effect of tool wear on cutting forces. It is continuously measurable without stopping the machining process and can be used in any kind of cutting operation.

Further tests showed that cutting speed has an important impact on the cutting force growth slope. Higher cutting 
Fig. 2 Passive cutting force increase due to tool wear during a pass with constant engagement (i.e. rigid workpiece) $-\mathrm{V}_{\mathrm{c}}=52.5$ $\mathrm{m} / \mathrm{min}, \mathrm{f}=0.1 \mathrm{~mm} / \mathrm{rev}, \mathrm{a}_{\mathrm{p}}=0.5$ $\mathrm{mm}$

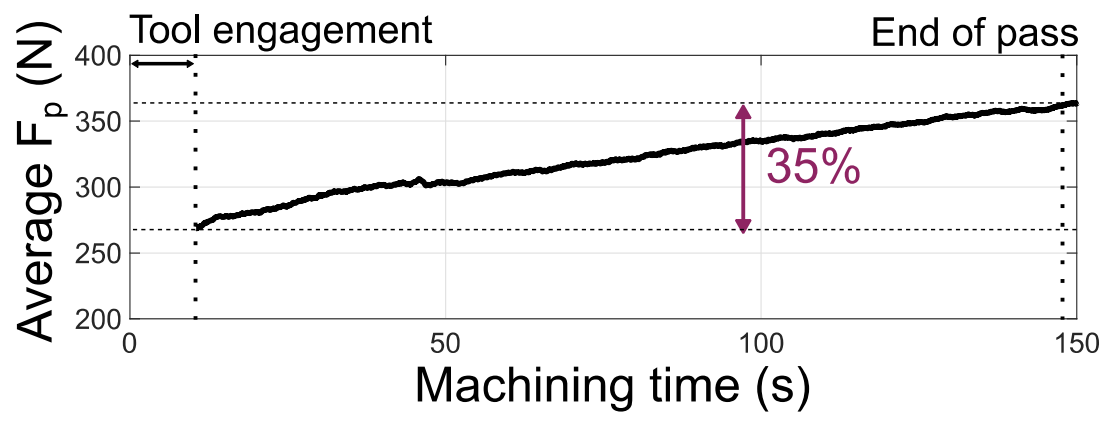

speeds lead to a steeper slope (article 2). Thus, a model designed to predict cutting forces evolution with tool wear for different cutting speed should take $V_{\mathrm{c}}$ into account in its formulation [12]. This research work focuses on the tests performed at $V_{\mathrm{c}}=52.5 \mathrm{~m} / \mathrm{min}$ so $\mathrm{V}_{\mathrm{c}}$ is not added to the following formulation.

\subsection{Mechanistic cutting force model development}

A mechanistic model considering tool wear is developed to model cutting forces evolution during the running-in and controlled wear regions. The cutting-edge discretisation method is used to identify the model coefficients. To do so, the cutting edge is separated in numerous elementary tools. Local cutting forces are expressed on each elementary tool $i$ in two directions as shown in Fig. 5: $f_{v i}$ parallel to the cutting speed direction (neglecting feed motion) and $f_{h i}$ normal to the cutting edge and $f_{v i}$. $f_{h i}$ is oriented toward the part.
The model is separated in two parts as shown in Eq. 1. The first part is the cutting forces obtained when using a fresh tool. This term is a linear function of the local cut thickness $h_{i}$. The width of the elementary tool $i$ is $b_{i}$. The $k_{c v} \cdot h_{i}$ term is the "cut effect" which mainly describes the local cutting force created by the sliding of the chip on the rake face. The $k_{e v}$ term is the "edge effect" which mainly describes the local cutting force created in the area where the cut material is separating from the workpiece. The second part of Eq. 1 is the influence of tool wear. This term is added to the "edge effect" to describe the increasing ploughing effect due to tool wear. It is modelled using the local cumulative removed volume crvol. This quantity can be continuously measured during the cutting process. Practically, crvol is computed by accumulating the local swept volume at each time step and for each elementary tool as pictured in Fig. 7. This method is flexible as it can be used for operations with varying engagement of the tool. During the identification process, as the cutting tests are performed with constant engagements, crvol is expressed as follows:

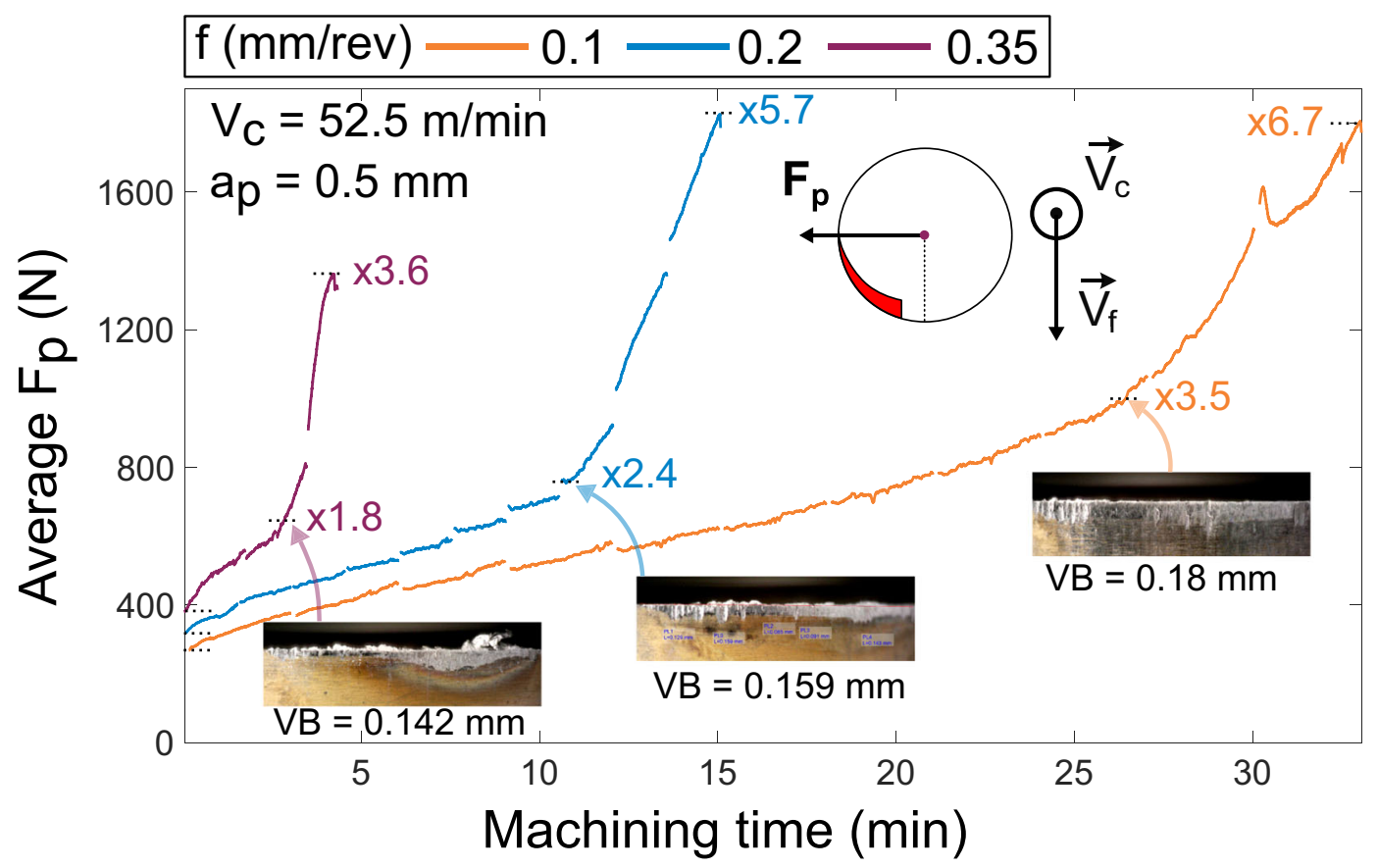

Fig. 3 Passive cutting force increases during tool life for three different feed values. The growth factors are displayed at the end of the controlled wear region and the end of tool life 
Fig. 4 Passive cutting force growth during tool life relative to the cumulative removed volume of material

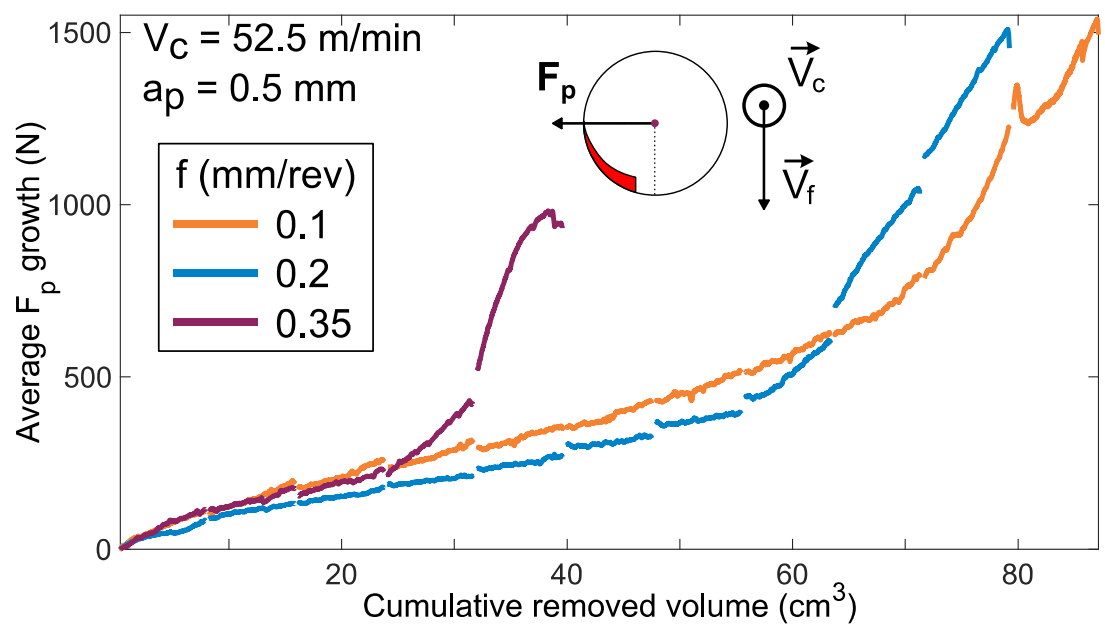

crvol $=b \cdot h \cdot V_{c} \cdot t$, where $t$ is the total machining time and $V_{c}$ is the cutting speed.

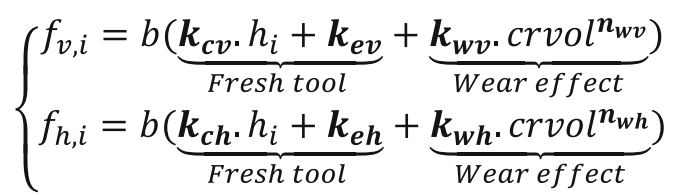

Once all local cutting forces are computed, they are projected on the machine coordinate system and summed to compute global cutting forces. Finally, a least mean square algorithm is used to identify the model coefficients to minimise the difference between modelled and measured forces. The identification results are gathered in Table 1. The data sample is composed of a discretisation of the cutting force evolution curves $\left(F_{c}, F_{f}\right.$ and $\left.F_{p}\right)$ which are continuously measured during the three cutting tests shown in Fig. 4. To summarise, the data sample is composed of 15 points per cutting force component and per cutting test (total of 135 experimental points). Simulation results and data sample used for the identification are displayed in Fig. 6. The three global cutting

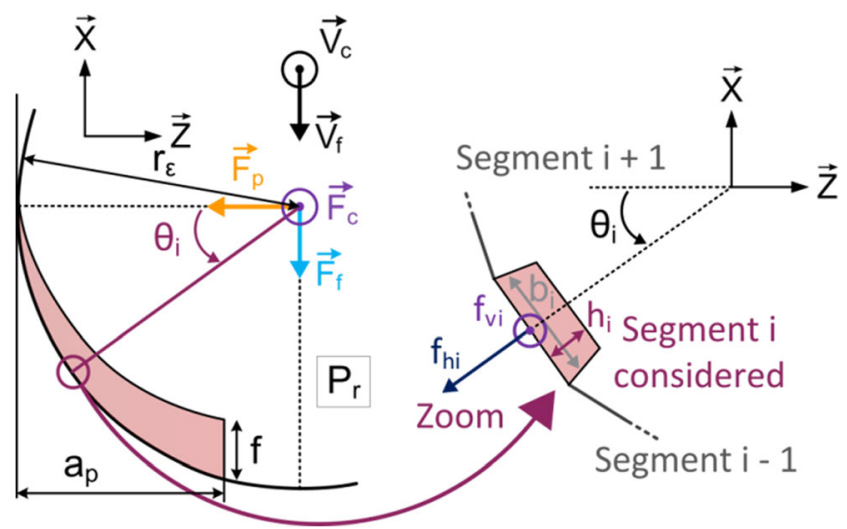

Fig. 5 Round tool engagement. Orientation of local and global forces in the machine coordinate system force components are accurately simulated during the running-in and controlled wear region of the tool life. Concerning the simulation of the passive cutting force $\mathrm{F}_{\mathrm{p}}$, which is the main responsible for in-process workpiece elastic deflection, the average relative error and the maximum error are equal to $4 \%$ and $11 \%$, respectively. The error tends to increase and reach a maximum at the end of the controlled wear region if the simulated slope is inaccurate. For example, the simulated $F_{p}$ slopes with 0.1 and 0.2 feeds are respectively slightly underestimated and overestimated. In a previous study, similar cutting tests displayed good repeatability during the running-in and controlled wear region [12]. However, the occurrence of the inflexion leading to the end of tool life may vary in time. Consequently, this model is to be used carefully so as not to exceed the end of the controlled wear period point beyond which it is not valid.

The developed model allows simulating cutting forces evolution during most of the tool life. The usage of a cumulative quantity such as the local removed volume can be generalised to different cutting operations and cutting tools.

\section{Modelling of location dependant stiffness}

Finite element models describing large workpieces are often composed of an important number of degrees of freedom.

Table 1 Cutting force model identification results

\begin{tabular}{|c|c|c|c|c|c|}
\hline \multirow[t]{2}{*}{ Global forces } & \multirow[t]{2}{*}{ Local forces } & \multicolumn{4}{|c|}{ Identified components } \\
\hline & & Fresh tool & & Wer & ffect \\
\hline \multirow[t]{2}{*}{$\mathrm{F}_{\mathrm{c}}$} & $\mathrm{f}_{\mathrm{v}}(\mathrm{N})$ & $\mathrm{k}_{\mathrm{cv}}\left(\mathrm{N} \mathrm{mm}^{-2}\right)$ & 2681 & $\mathrm{k}_{\mathrm{wv}}$ & 51 \\
\hline & & $\mathrm{k}_{\mathrm{ev}}\left(\mathrm{N} \mathrm{mm}^{-1}\right)$ & 54 & $\mathrm{n}_{\mathrm{wv}}$ & 0,46 \\
\hline \multirow[t]{2}{*}{$\mathrm{F}_{\mathrm{f}}, \mathrm{F}_{\mathrm{p}}$} & $\mathrm{f}_{\mathrm{h}}(\mathrm{N})$ & $\mathrm{k}_{\mathrm{ch}}\left(\mathrm{N} \mathrm{mm}^{-2}\right)$ & 827 & $\mathrm{k}_{\mathrm{wh}}$ & 83 \\
\hline & & $\mathrm{k}_{\mathrm{eh}}\left(\mathrm{N} \mathrm{mm}^{-1}\right)$ & 119 & $\mathrm{n}_{\mathrm{wh}}$ & 0,75 \\
\hline
\end{tabular}



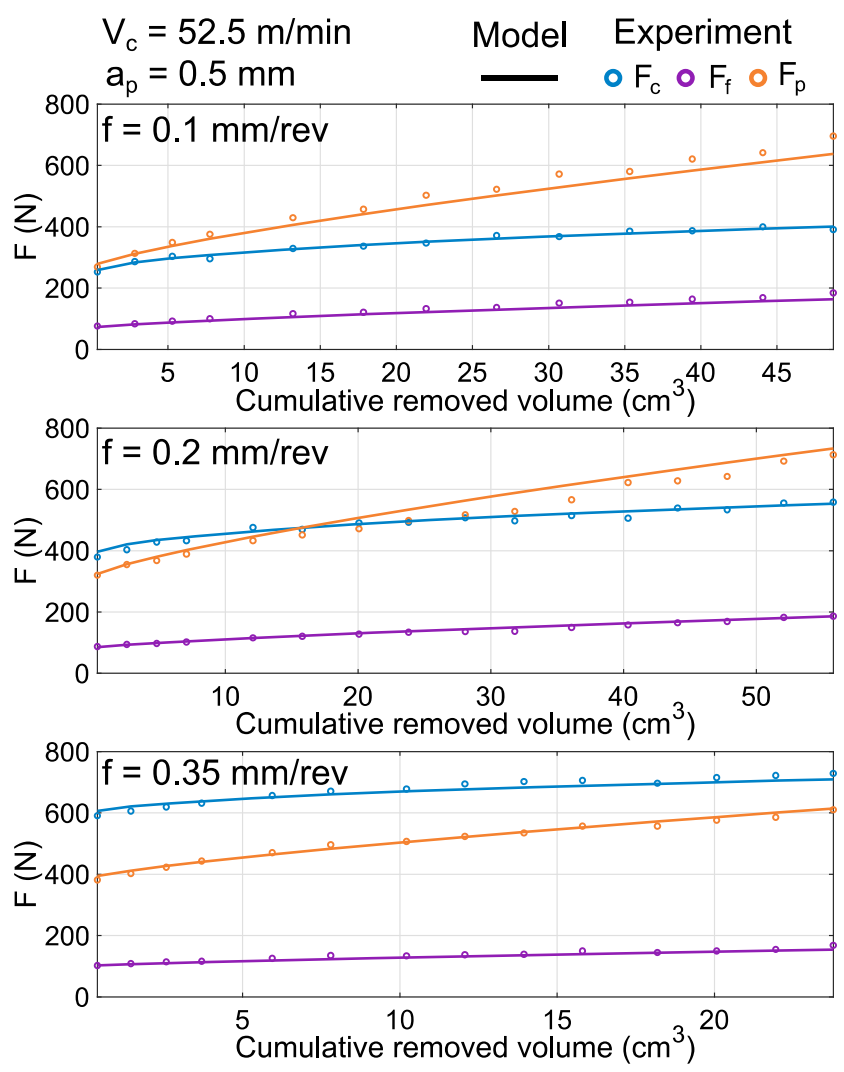

Fig. 6 Cutting force evolution simulation during running-in and controlled wear regions vs experimental measurements

Using these models to simulate workpiece displacement for several tool locations is time-consuming and hence not practicable. In order to reduce the computational time, a reduced model using Rayleigh-Ritz approach [10] may be used to describe the workpiece deflection.

The key principle of this approach, when a machining operation is simulated, is that only the low-frequency phenomena, i.e., the first modes of vibrations, are significantly contributing to the global deflection of the machining system. Then, the workpiece model initial degree of freedom vector $q_{w}$ containing $N$ degrees of freedom can be approximated in the following form: $q_{w}=\varphi_{w}$. $\alpha_{w}$. In this formulation, $\alpha_{w}$ is the new unknown reduced degree of freedom vector of size $n$, where $n \ll N$. And $\varphi_{w}$ is a rectangular matrix of size $N x n$ containing the shape functions associated to the $n$ first eigen modes chosen to describe the workpiece response. The amount $n$ of chosen eigen modes depends on the modal density for low eigen frequencies. However, for simple workpieces, this number is quite low $(<10)$. It results in a drastic reduction of the degree of freedom allowing for rapid computation of static balance under machining loads.

The most time-consuming part of this approach is the computation of the matrix $\varphi_{w}$. To do so, finite element modal analysis is performed on the initial workpiece model. Boundary conditions are always complex to model, and an updating strategy was conducted (boundary stiffness calibration) to best describe the real machining system response. Iterations are performed to minimise the difference between simulated eigen modes and measured ones. Eigen modes are measured on the machining system, i.e. when the workpiece is clamped and ready for machining. The system transfer function is obtained with hammer impacts and accelerometers placed on the workpiece.

\subsection{Model reduction applied to the studied case}

Hammer impact tests are performed in situ on the disc presented in Fig. 1 before machining while it is clamped on its shaft. The acquired system transfer function is modelled and the first eigen frequencies are extracted (Table 2). Then, a FE model of the shaft assembly is set up based on its nominal dimensions. The disc is modelled perfectly flat and with a constant thickness equal to the average disc thickness measured experimentally $(2.96 \mathrm{~mm})$. The flatness error measured at $60 \mu \mathrm{m}$ is not modelled in a static context. The rest of the machine is considered as an infinite rigid body. After verification by simulation, because the workpiece is so thin, only its related eigen modes are relevant to describe the system dynamical response during machining. A first modal analysis is performed with the nominal geometry and nominal material data: Young's modulus $=208 \mathrm{GPa}$, density $=8220 \mathrm{~kg} \cdot \mathrm{m}^{-3}$ and Poisson's ratio $=0.32$. The simulated eigen frequencies of this original model are shown in Table 2 . The high values of relative error show that this model poorly describes the system dynamic response. The FE model boundary conditions are then optimised to better fit the real experimental set-up. For example, the rigid clamping between disc and shaft is not really a joint without displacement between disc and shaft (i.e. $\mathrm{u}_{\mathrm{disc}}=\mathrm{u}_{\mathrm{shaft}}$ in all nodes). Moreover, the optimisation homogenises the ratio between simulated and measured eigen frequencies. Indeed, the low-frequency modes are more sensitive to boundary conditions than the high-frequency ones. Once the ratio is consistent for all measured modes, it is brought closer to 1 by adjusting the material Young's modulus. In this case, the optimised Young's modulus is equal to $191 \mathrm{GPa}$ which is $8 \%$ lower than the nominal value for Inconel 718. The material density and Poisson's ratio are unchanged. The simulated eigen frequencies obtained with the optimised FE model are shown in Table 2 and the relative error with experimental measurements does not exceed $2.4 \%$.

The first 10 eigen frequencies are selected to build the reduced modal basis describing the machining system. The matrix $\varphi_{w}$ is then computed following a modal analysis on the optimised FE model.

In the next section, the cutting force and stiffness models previously developed are implemented in the framework introduced in Section 5.1. A face-turning operation on a disc is simulated using this framework and the results are compared with reality. 
Table 2 Workpiece eigen frequencies, measured vs simulated with the original and optimized models

\begin{tabular}{llllll}
\hline & \multicolumn{2}{l}{ Original model } & & \multicolumn{2}{l}{ Optimised model } \\
\cline { 2 - 3 } \cline { 5 - 6 } Measured (Hz) & Simulated (Hz) & Relative error & & Simulated (Hz) & Relative error \\
\hline 766 & 803 & $4,8 \%$ & & 760 & $-0,8 \%$ \\
759 & 803 & $5,8 \%$ & & 760 & $0,1 \%$ \\
842 & 940 & $11,6 \%$ & & 855 & $1,5 \%$ \\
997 & 1116 & $11,9 \%$ & & 1021 & $2,4 \%$ \\
1032 & 1116 & $8,1 \%$ & & 1022 & $-1,0 \%$ \\
1846 & 1957 & $6,0 \%$ & & 1851 & $0,3 \%$ \\
1878 & 1957 & $4,2 \%$ & & 1851 & $-1,4 \%$ \\
3138 & 3305 & $5,3 \%$ & 3153 & $0,5 \%$ \\
3181 & 3305 & $3,9 \%$ & 3153 & $-0,9 \%$ \\
\hline
\end{tabular}

\section{Undercut simulation and compensation}

\subsection{Deflection modelling framework}

The modelling methodology is based on an incremental approach to reproduce the relative motion between the cutting tool and the workpiece. Static workpiece deflection is considered during the machining operation. The flowchart in Fig. 7 summarises the key steps of the simulation approach. The workpiece geometry is filled with dexels $[15,16]$. The tool rake face is divided in several elementary tools and filled with triangular elements. The tool rake face and workpiece interference are then computed at each time step and the swept volume is removed from the workpiece geometry (i.e. by updating of the dexel carpet). This approach is advantageous compared to analytical approaches which are restricted to specific usage. Indeed, it only requires a description of the tool and workpiece geometry as well as the tool path to compute the cutting amount. User-defined laws are used to compute cutting forces depending on the current cutting conditions and quantity of removed material. The mechanical problem is solved by using a dynamic non-linear time domain approach. The reduced model is used to determine workpiece stiffness by using Rayleigh-Ritz approach [10]. It greatly shortens computational times. This versatile approach is thoroughly detailed in [17].

\subsection{Face-turning simulation on thin disc}

A face-turning operation is simulated on a disc with the previous framework. The nominal cutting conditions are $\mathrm{V}_{\mathrm{c}}=52.5 \mathrm{~m} / \mathrm{min}$, $\mathrm{f}=0.1 \mathrm{~mm} / \mathrm{rev}$ and $\mathrm{a}_{\mathrm{p}}=0.465 \mathrm{~mm}$. The face-turning operation is performed from the radial position $68.5 \mathrm{~mm}$, which is the maximum disc radius, to $29 \mathrm{~mm}$ using constant cutting speed. The workpiece geometry is filled with dexels whose axes are in the axial direction. The dexel lateral size is $0.03 \mathrm{~mm}$ and the numerical time step used for the simulation is equal to $0.5 \mathrm{~ms}$. The tool motion with respect to the part is simulated, during one time step, by a straight segment. The previous data induced chord error on the tool trajectory that does not exceed $1 \mu \mathrm{m}$. These two settings are essential to precisely describe the circular tool trajectory and to ensure numerical stability by cutting a sufficient amount of cut dexel at each time step, approximately 15 dexels in this case. The round cutting tool is defined by a 4-mm radius arc and discretised in 40 elements with a $0.14-\mathrm{mm}$ width in the engaged edge (chord error $0.6 \mu \mathrm{m}$ ). The workpiece mechanical model determined in Section 4.1 is implemented. The cutting tool is considered perfectly rigid. At last, the cutting force model described in Eq. 1 and the model coefficients in Table 1 are filled in a user defined cutting law. For the sake of giving an order of magnitude, the simulation time is $33 \mathrm{~min}$ on a computer with a $2.8 \mathrm{GHz} 4$-cores processor and 16 Go of RAM operating on a 64 bits system. This can be compared with the actual machining time which is 2.3 minutes. The 3D geometry of the whole machined surface is computed even if in the study only a profile $P_{S}$ along the radius of the machined surface is extracted (axisymmetric problem).

On the one hand, the simulated undercut is computed as the difference between simulated and nominal depth of cut: $U_{\mathrm{s}}=$ $0.465-\mathrm{P}_{\mathrm{s}}$, with assumption of initial form error equal to zero. On the other hand, the average undercut $U_{m}$ is measured on the real disc after the cutting test. The two undercuts $U_{s}$ and $U_{m}$ are displayed on Fig. 8. The error between measured and simulated undercut is $\varepsilon=\mathrm{U}_{\mathrm{s}}-\mathrm{U}_{\mathrm{m}}$.

On the black experimental curve, the undercut tends to decrease as the tool gets closer to the disc anchor point, where it is the stiffest. However, the undercut is slightly lower at the beginning of the pass during the tool engagement transient regime. The simulation reproduces this transient regime, but it appears shorter than the experimental one. The most likely explanation for this phenomenon is that, for low cutting thickness, and therefore when the tool enters the material, the cutting law used is not sufficiently faithful. The maximum error reached in this region is equal to $\varepsilon_{1}=26 \mu \mathrm{m}$.

Otherwise, during the steady state, the simulated undercut is lower than the one obtained experimentally. The maximum absolute error is $\varepsilon_{2}=-18 \mu \mathrm{m}$ at the radial position $52 \mathrm{~mm}$. To 
Fig. 7 General algorithm used to simulate a cutting operation

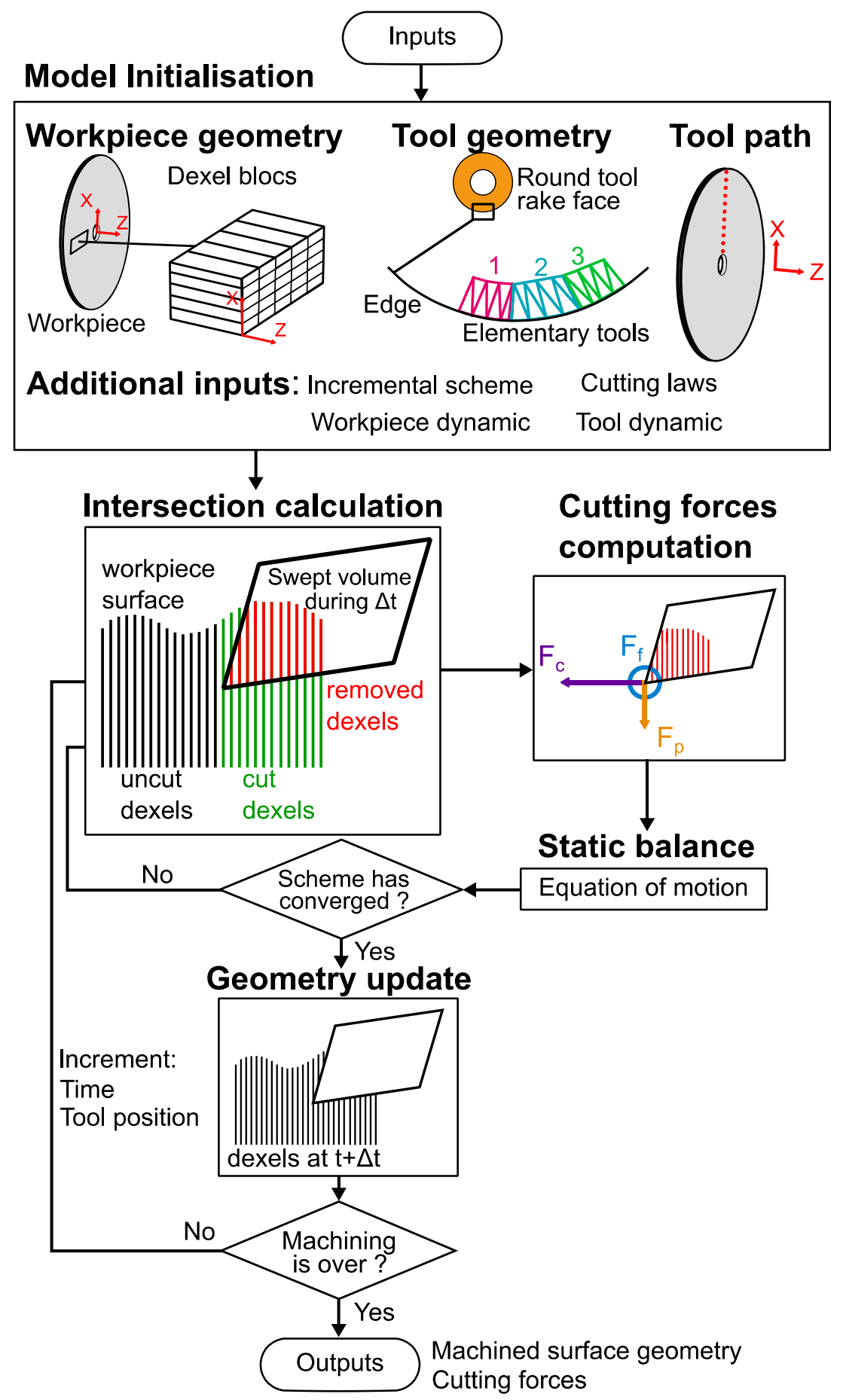

better understand this error, experimental and numerical passive cutting force evolutions are displayed in Fig. 9 for a rigid workpiece and the studied flexible disc. During the test on a rigid workpiece, with a constant tool engagement, the cutting force model is able to accurately predict the passive cutting force evolution with tool wear ( $80 \mathrm{~N}$ in $2.3 \mathrm{~min}$ ). During the cutting test performed on the flexible disc (green curve), the passive cutting force increases and reaches a maximum at the end of the pass where the disc is the stiffest. Furthermore, the increase in passive cutting force due to tool wear appears to occur faster than during the test on the rigid workpiece. Even though the cumulative removed volume is $23 \%$ lower during the test on the flexible disc, the force level reached at the end of the pass are comparable with the one obtained on a rigid workpiece. The most obvious explanation is that cutting force evolution during tool life is not perfectly repeatable. Another possibility is that the proposed model is not suitable for varying engagements. One can notice that the passive cutting force 


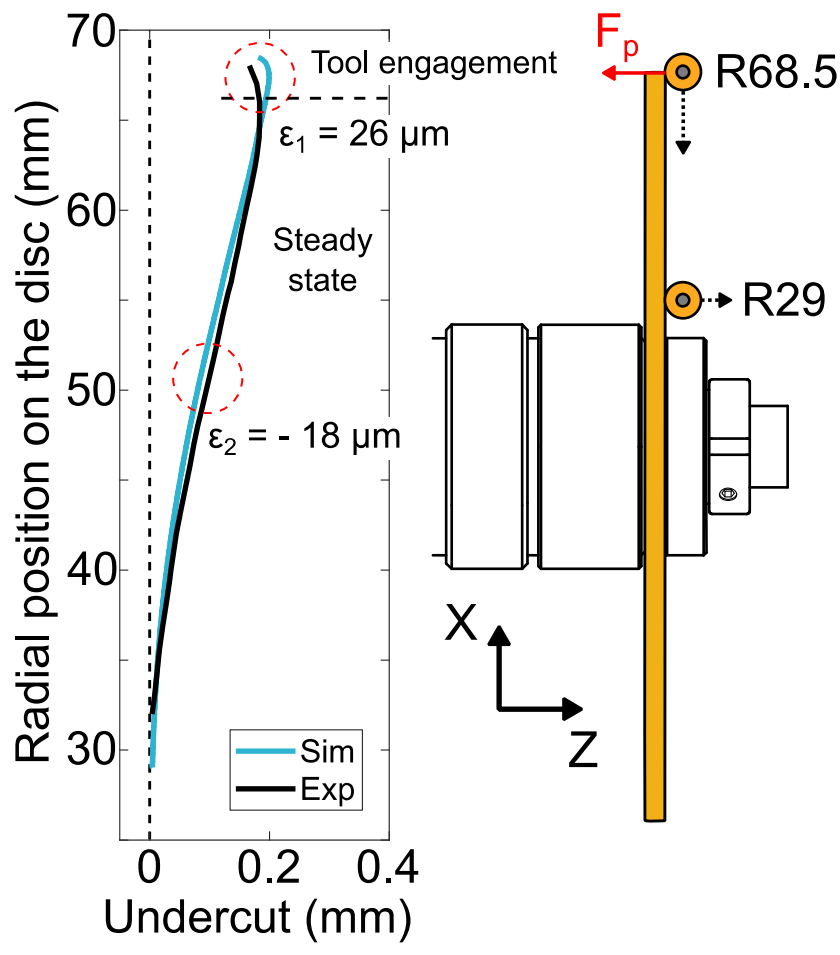

Fig. 8 Undercut simulation vs experimental measurements

reached at the end of the simulation on the flexible disc (blue curve) is consistent with the $23 \%$ drop in removed volume which represents $30 \mathrm{~N}$ according to the force model. However, the cutting force error between measured and simulated data increases and reaches a maximum value at the end of the pass equal to $50 \mathrm{~N}$. Consequently, the error between the experimental and numerical undercut in the steady state region in Fig. 8 is mostly due to the undervaluation of the passive cutting force.

In the studied case, the cutting force model is valid for tests with constant tool engagements ( $c f$. Section 3.2). However, the cutting test on a flexible disc shows that the proposed local cumulative removed volume term might not be suitable to model the effect of tool wear with varying engagement. Tool wear seems to be more important for small depth of cut than predicted

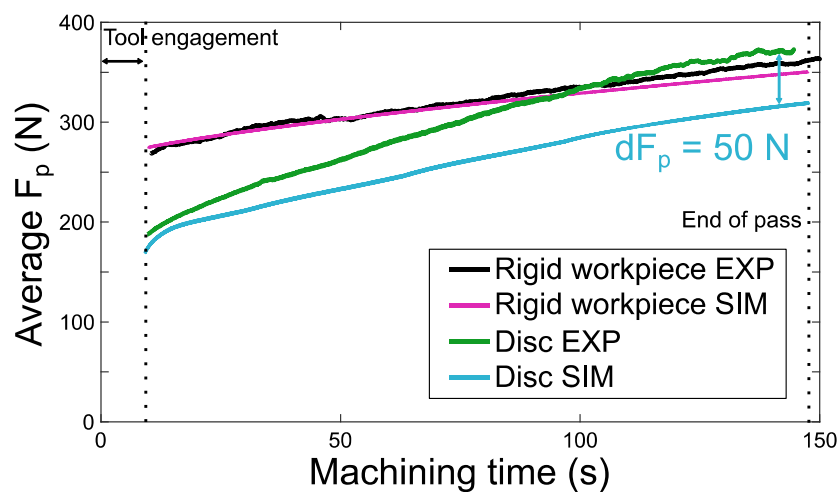

Fig. 9 Passive cutting force evolution - experimental vs simulation for a rigid workpiece and the flexible disc 1 by only taking the cumulative removed volume into account. It would be interesting to test this model with more complex contouring operations with different portions of the cutting edge being engaged along the tool path in order to design a more effective cutting law.

\subsection{Discussions on the method}

This method may appear cumbersome as a hammer impact test and a FE model optimisation have to be performed. Indeed, this procedure requires high experimental and numerical skills. However, when machining high-added value parts with large dimensions and thin portions, engineers are struggling to choose a tool path. Conservative approaches tend to limit the depth of cut and require frequent checks of part dimensions. The target dimensions are finally reached after several iterations. This is time-consuming and labour-intensive. The methodology presented in this study may help to choose a tool path for effective finishing operations. It is intended to be used for finishing operations on high-added value workpieces where the important economical stakes justify the use of a high skill procedure. This versatile methodology has been successfully applied to more realistic cases, e.g. turbine blades in [18].

Moreover, the FE model optimisation is intended to obtain an accurate flexibility model of the machining system. However, if the aim is to solely model static workpiece deflection, the optimisation step might not be necessary. Indeed, it is possible to use the original FE model based on nominal dimensions and material data and obtain satisfying results. The simulated machined surface average profile using the original FE model and the optimised one are compared in Fig. 10. The original model is stiffer than the optimised one due to the higher Young's modulus and overly constraining boundary conditions used. As a result, the simulated undercut is underestimated with the original FE model. The maximal absolute error between simulated and experimental results, obtained with the original FE model in the steady state region, is equal to $-31 \mu \mathrm{m}$. The optimisation step allows reducing this error by $42 \%$.

The simulation strategy relies on an accurate prediction of cutting forces and workpiece stiffness. Tool wear has a significant impact on cutting forces during tool life, especially for refractory alloys such as Inconel 718 . The proposed cutting force model is able to predict cutting forces evolution with constant engagement. There is a need to develop more robust models able to predict cutting force evolutions with varying engagements. A further step would be to use this method to develop compensating strategies in order to control or compensate the undercut. For example, considering the fact that a cutting force and a workpiece stiffness model are available, it would be straightforward to develop a compensating strategy with a constant engagement constraint. Indeed, with this 


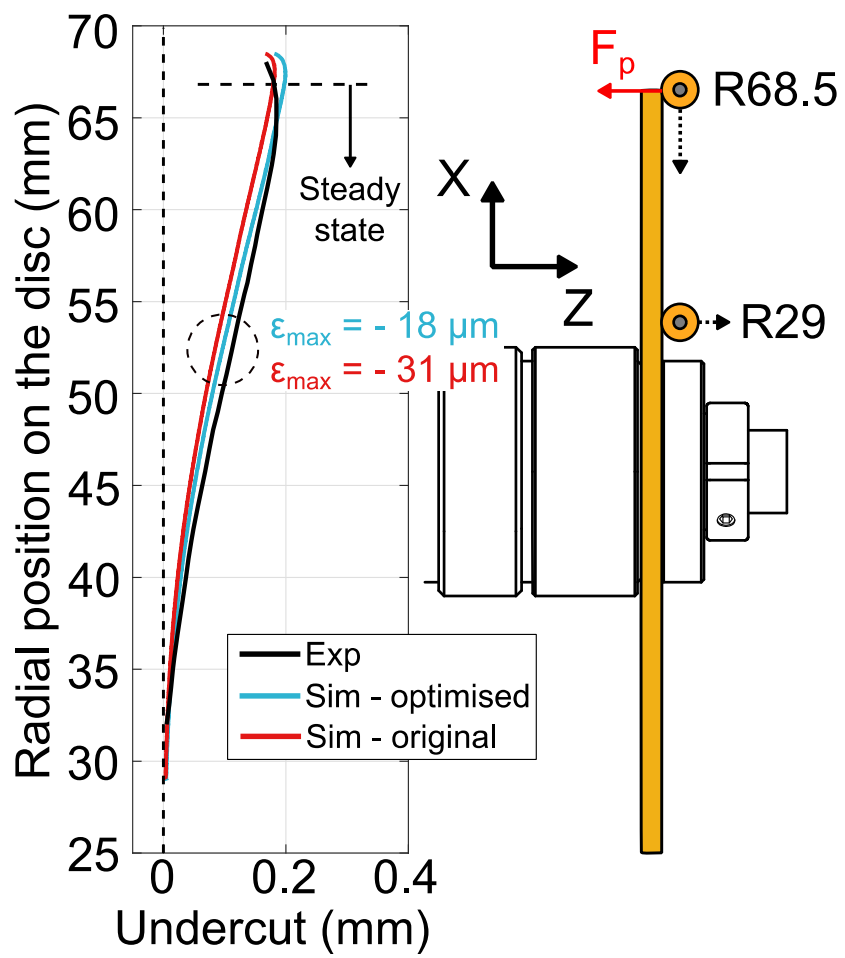

Fig. 10 Undercut simulation vs experimental measurements. Result comparison between the original and optimised FE models

constraint, there is a direct relation between cutting forces and the resulting workpiece displacement.

\section{Conclusions}

This study presents a versatile approach to simulate the undercut error which appears when turning thin-walled workpieces. An innovative coupling of workpiece stiffness model with a cutting force model considering tool wear evolution is proposed in a general machining simulation framework. A methodology to create a reduced workpiece stiffness model based on Rayleigh-Ritz approach is used. The method is general and allows for major computing time reduction. It requires high numerical and experimental skills which are justified for highadded value parts. In this study, a mechanistic cutting force model taking tool wear into account is presented. It correctly predicts cutting forces evolution during tool life for constant engagement tests. However, the variability of cutting force evolution with tool wear remains an obstacle for the development of a robust model.

The presented framework is usable for a large variety of cutting operations. A major helpful step to enhance the cutting process simulation would be to develop robust cutting force models. Also, it would be interesting to add the contribution of machining induced residual stresses, and those present prior to machining, to workpiece distortion. Finally, as dynamics occurs in many thin-walled machining these dynamics will be added in future work to simulate the effect of vibrations on geometrical errors.

Code availability No code are made available by the authors.

Author's contribution Bastien Toubhans: Conceptualization, methodology, writing-reviewing and editing. Philippe Lorong: Conceptualization, methodology, supervision, validation. Guillaume Fromentin: Conceptualization, methodology, supervision, validation. Fabien Viprey: Conceptualization, methodology, supervision, validation. Habib Karaouni: Validation, resources.

Data Availability No data or material are made available by the authors.

\section{Declarations}

Ethical approval The authors have read and applied the ethical rules stated in the guidelines for authors.

Consent to participate Not applicable.

Consent to publish Not applicable.

Conflict of interest The authors declare that they have no conflict of interests.

\section{References}

1. Ma J, He G, Liu Z, Qin F, Chen S, Zhao X (2018) Instantaneous cutting-amount planning for machining deformation homogenization based on position-dependent rigidity of thin-walled surface parts. J Manuf Process 34(Part A):401-411

2. Chen W, Xue J, Tang D, Chen H, Qu S (2009) Deformation prediction and error compensation in multilayer milling processes for thin-walled parts. Int J Mach Tools Manuf 49(11):859-864

3. Yan Q, Luo M, Tang K (2018) Multi-axis variable depth-of-cut machining of thin-walled workpieces based on the workpiece deflection constraint. Comput Aided Des 100:14-29

4. Huang T, Zhang X-M, Ding H (2017) Tool orientation optimization for reduction of vibration and deformation in ball-end milling of thin-walled impeller blades. Procedia CIRP 58:210-215

5. Wang J, Ibaraki S, Matsubara A (2017) A cutting sequence optimization algorithm to reduce the workpiece deformation in thin-wall machining. Precis Eng 50(Supplement C):506-514

6. Fei J, Xu F, Lin B, Huang T (2020) State of the art in milling process of the flexible workpiece. Int J Adv Manuf Technol 109(5):1695-1725

7. Dépincé P, Hascoët J-Y (2006) Active integration of tool deflection effects in end milling. Part 2. Compensation of tool deflection. Int $\mathrm{J}$ Mach Tools Manuf 46(9):945-956

8. Dépincé P, Hascoet J-Y (2006) Active integration of tool deflection effects in end milling. Part 1. Prediction of milled surfaces. Int J Mach Tools Manuf 46(9):937-944

9. Ratchev S, Govender E, Nikov S, Phuah K, Tsiklos G (2003) Force and deflection modelling in milling of low-rigidity complex parts. J Mater Process Technol 143-144:796-801

10. Bathe K-J (2006) Finite element procedures. Klaus-Jurgen Bathe

11. Arrazola PJ, Garay A, Fernandez E, Ostolaza K (2014) Correlation between tool flank wear, force signals and surface integrity when 
turning bars of Inconel 718 in finishing conditions. Int J Mach Mach Mater 15(1-2):84-100

12. Toubhans B, Fromentin G, Viprey F, Karaouni H, Dorlin T (2020) Machinability of inconel 718 during turning: Cutting force model considering tool wear, influence on surface integrity. J Mater Process Technol:116809

13. Sawangsri W, Cheng K (2016) An innovative approach to cutting force modelling in diamond turning and its correlation analysis with tool wear. Proc Inst Mech Eng Part B J Eng Manuf 230(3):405-415

14. Cheng K (2008) Machining dynamics: fundamentals, applications and practices. Springer Science \& Business Media

15. Lee SW, Nestler A (2012) Virtual workpiece: workpiece representation for material removal process. Int J Adv Manuf Technol 58(58):443-463
16. Van Hook T (1986) Real-time shaded NC milling display. ACM SIGGRAPH Comput. Graph

17. Coffignal G, Lorong P, Illoul L (2015) A general method to accurately simulate material removal in virtual machining of flexible workpieces. Technical Report, PIMM laboratory, 40 pages

18. Lorong P, Coffignal G, Balmes E, Guskov M, Texier A (2012) Simulation of a finishing operation: milling of a turbine blade and influence of damping. Eng Syst Design Anal 44878:89-98 